\title{
๑) $\triangle \Theta$ As fontes da pedagogia trabalhista de António Sérgio
}

\author{
João Príncipe*
}

Resumo: Porventura o traço mais saliente da proposta educativa de António Sérgio para o Portugal republicano é a de ser uma pedagogia trabalhista, em que a preparação para e pelo trabalho é uma condição para a construção de pessoas autónomas, membros de uma sociedade baseada na cooperação. Para Sérgio, a correcta operacionalização dos novos métodos de ensino, valorizadores dos interesses imanentes das crianças, implicava uma fundamentação filosófica séria, um modelo antropológico coerente no qual uma concepção do trabalho humano é fulcral. O propósito deste artigo é o de articular sinteticamente os fundamentos da sua proposta trabalhista do valor educativo e social de um ideal de trabalho, cuidando das fontes estrangeiras de inspiração da mesma, entre as quais destacaremos Pierre-Joseph Proudhon (1809-1865), John Dewey (1859-1952) e Georg Kerschensteiner (1854-1932). Mostra-se que Sérgio soube encontrar uma fundamentação que junta reflexões daqueles pensadores, estabelecendo uma relação habitualmente ignorada entre os pedagogos seus, e nossos, contemporâneos. Pretende-se assim, recorrendo aos métodos da história das ideias, valorizadores da genealogia e da contextualização intelectual, homenagear, no cinquentenário da sua morte, um dos paladinos da Escola Nova em Portugal,

Doutor em Epistemologia e História das Ciências e das Técnicas pela Paris Diderot University (UN. PARIS VII). Professor Universidade de Évora (UEVORA). E-mail: jpps25041974@gmail.com. ORCID: https://orcid.org/0000-0003-0235-9079. 
dissipando algumas dúvidas sobre as reais motivações daquele Movimento pedagógico progressista no Portugal Republicano.

Palavras Chave: António Sérgio. Pedagogia trabalhista. Proudhon. Dewey. Kerschensteiner.

\title{
The sources of the labour pedagogy of António Sérgio
}

\begin{abstract}
Perhaps the most striking feature of the thought of António Sérgio (1883-1969) is his proposal of a labour pedagogy, where the preparation for and through work is a condition for the construction of persons that live in a society based on cooperation. For Sérgio the proper implementation of new teaching methods, that respect the true interests of children, implies a serious philosophical reflection, a coherent anthropological model in which a conception of human labour is critical. Our purpose is to articulate his philosophical reflections that justify the educational and social value of human labour, taking care of foreign sources of inspiration, among which are Pierre-Joseph Proudhon (1809-1865), John Dewey (1859-1952) and Georg Kerschensteiner (1854-1932). It is shown that Sérgio brought together reflections of those thinkers, establishing a harmonic philosophical communion, usually ignored. By using the methods of the history of ideas that value the search of genealogy and intellectual context, we honour, in the fiftieth anniversary of his death, one of the paladins of the Éducation Nouvelle in Portugal, showing the real motivations of that progressive educational movement during the First Portuguese Republic.
\end{abstract}

Keywords: António Sérgio. Labour pedagogy. Proudhon. Dewey. Kerschensteiner. 


\section{Les sources de la pédagogie travailliste d'António Sérgio}

Résumé: Peut-être la caractéristique la plus frappante de la pensée éducationnelle d'António Sérgio (1883-1969) est son pari dans une pédagogie du travail, où la préparation pour et par le travail est une condition pour la construction de personnes qui vivent dans une société fondée sur la coopération. Pour Sérgio, la mise en œuvre de nouvelles méthodes d'enseignement, qui respectent les véritables intérêts des enfants, implique une réflexion philosophique sérieuse, un modèle anthropologique cohérent pour lequel une conception du travail humain est essentielle. Notre but est d'articuler ses réflexions philosophiques qui justifient la valeur éducative et sociale du travail humain, en prenant soin des sources étrangères d'inspiration: Pierre-Joseph Proudhon (1809-1865), John Dewey (18591952) et Georg Kerschensteiner (1854-1932). On démontre que Sérgio a rassemblé des réflexions de ces penseurs, en établissant une communion philosophique harmonique, généralement ignorée par les pédagogues et philosophes de son temps et du notre. En utilisant les méthodes de l'histoire des idées qui reconstruisent des généalogies et des contextes intellectuels, nous rendons hommage, dans le cinquantième anniversaire de sa mort, à l'un des paladins de l'Éducation Nouvelle au Portugal, en montrant les motivations réelles de ce mouvement éducatif pendant la Première République portugaise.

Mots clés: António Sérgio. Pédagogie du travail. Proudhon. Dewey. Kerschensteiner. 


\section{Introdução}

António Sérgio (1883-1969) é um dos mais destacados pedagogos portugueses do período da Primeira República Portuguesa, intimamente ligado ao movimento da Escola Nova, e um dos maiores intelectuais portugueses do século XX, tendo mantido desde sempre boas relações com figuras da intelectualidade brasileira como Sílvio Romero ou Gilberto Freire, as quais reflectem o seu cosmopolitismo e a sua leitura da história lusitana, de cujo colonialismo foi sempre crítico, ao salientar o carácter parasitário do mesmo. O seu pensamento pedagógico foi se constituindo na década de 1910 junto com o seu pensamento histórico sociológico sendo ele pensado como remédio ou solução para um diagnóstico histórico que denuncia as desigualdades sociais numa nação cujo destino esteve, desde 1500, unido à expansão e à globalização da economia à escala mundial.

Porventura o traço mais saliente da proposta educativa de António Sérgio (AS) para o Portugal da Primeira República é a de ser uma pedagogia trabalhista, onde a preparação para e pelo trabalho é uma condição para a construção de pessoas autónomas que são membros de uma sociedade baseada na cooperação. Ela é pensada para combater os vícios ancestrais do parasitismo e do comunitarismo, cuja versão contemporânea é o comunitarismo de Estado, caracterizado pelo clientelismo e bacharelismo, implicando uma reforma de mentalidade que visa, numa primeira fase, criar uma elite capaz, imbuída de espírito democrático, melhorista e inovador. A sua pedagogia centra-se no ideal de self-government, apoiada no ideal municipalista de Alexandre Herculano (1810-1877), e numa noção de trabalho criativo, sendo pensada de um 
modo cosmopolita, procurando adaptar soluções estrangeiras ao caso português.

AS havia publicado em 1909 o livro Notas sobre Antero de Quental, no qual analisou a resposta espiritualista de Antero (1842-1891) ao cientismo positivista e à extrapolação para a moral da conjunção entre determinismo mecanicista e darwinismo social do struggle for life, conjunção que mina o ideal de liberdade e a autonomia da voz da consciência; o pampsiquismo anteriano casa o hegelianismo, que vê na História o progresso do Espírito, com uma leitura teleológica da evolução das espécies que identifica um progresso no sentido das formas superiores. Este optimismo cósmico na longue durée era acompanhado pelo reconhecimento e análise do estado de decadência nacional e pela vontade de o corrigir, na linha de um Alexandre Herculano, propondo Antero que se opusesse "à inércia industrial a iniciativa do trabalho livre, a indústria do povo para o povo, não dirigida e protegida pelo Estado, mas espontânea" (SÉRGIO 1914a/2008, p. 52).

Com o início da Primeira República, AS abandonou o projecto de uma carreira de oficial da Marinha e foi-se interessando cada vez mais pelas questões ligadas ao nosso destino colectivo, seguindo o exemplo da geração de 1870. Iniciando um percurso de publicista e de intelectual civicamente empenhado, AS participará na Sociedade de Estudos Pedagógicos desde a sua criação em 1910 (com João de Barros, etc.) e a partir de 1912 integrará o núcleo lisboeta do movimento cultural e cívico Renascença Portuguesa (RP), o qual cria Universidades Populares e desenvolve importante actividade editorial. AS será presença constante no debate republicano sobre a função da Escola. Se entre os pedagogos 
republicanos há unanimidade em torno do valor da escolarização para o progresso, existe clara divergência de opiniões quanto ao mérito de reformas centradas na alfabetização, a qual remete para o binómio instrução-educação, entendendo-se por instrução a aquisição de conhecimento básicos (como o ler escrever e contar) e por educação a formação integral do indivíduo onde é fundamental o cultivar de uma atitude moral, cívica e social. AS afirmará resolutamente o primado da educação, seguindo assim a posição de Adolfo Coelho (1847-1919), um dos camaradas de Antero nas Conferências do Casino (PINTASSILGO, 1998, p. 62-66).

Em 1914, António e Luísa Sérgio rumam a Genebra, onde irão estudar no recém criado Institut Jean-Jacques Rousseau (1912). Esta Escola de Ciências da Educação da Universidade de Genebra fornece um diploma correspondente a um curso de pós-graduação com a duração de dois anos. O Instituto é fundado por Édouard Claparède e dirigido por Pierre Bovet sendo então o centro europeu do movimento da Educação Nova, movimento que se irmana com o outro lado do Oceano, com a Educação progressista de John Dewey. É durante o período de Genebra que AS desenvolve o núcleo do seu pensamento pedagógico trabalhista.

$\mathrm{O}$ propósito deste artigo será o de articular sinteticamente os fundamentos da sua proposta trabalhista do valor educativo e social de um ideal de trabalho, cuidando das fontes estrangeiras de inspiração da mesma, entre as quais destacaremos Pierre-Joseph Proudhon (1809-1865), 
John Dewey (1859-1952), Èdouard Claparède (1873-1940) e Georg Kerschensteiner (1854-1932). ${ }^{1}$

\section{As reflexões sergianas}

AS termina a sua conferência de apresentação da Renascença Portuguesa, dada no Rio de Janeiro em julho de 1913, citando o autor das Causas da decadência dos povos peninsulares para quem 'o espírito da idade moderna' é de "trabalho e indústria: a riqueza e a vida das nações têm de se tirar da actividade produtora, e não já da guerra esterilizadora”. Nas palavras de AS há que reunir "Trabalho, Ciência e Revolução, mas trabalho de libertação e de justiça; mas ciência que honesta fosse e criadora; mas pacífica revolução que regenerasse as nossas almas"; o futuro autor dos Ensaios propõe portanto uma "doutrina da redenção pelo esforço e pela cultura, pelo trabalho e pela luz". AS é muito claro neste texto quanto às inspirações socialistas que o movem, filiando-se numa linhagem de socialismo ético de matriz solidarista, linhagem alternativa à de Karl Marx, e que não faz da luta de classes o centro das preocupações, optando antes por uma via reformista (SÉRGIO, 1914a/2008, pp. 52-53).

AS escreve em 1914: "A nossa futura pedagogia deverá ser, essencialmente, uma pedagogia do trabalho e da organização social do trabalho" (SÉRGIO, 1914b, p. 96). Na advertência ao opúsculo Educação Cívica (1915), AS distingue entre o seu conceito de 'educação profissional' e o de 'educação técnica':

\footnotetext{
${ }^{1}$ Todas as traduções são nossas. Usaremos as seguintes abreviaturas: António Sérgio - AS; John Dewey - JD.
} 
entendemos por educação profissional a educação genérica do trabalho, em que se toma o exercício de uma arte usual como meio educativo, e em que se concede especial valor ao trabalho em comunidade, trabalho em que a acção de um indivíduo se vai inserir num plano geral (...) $\mathrm{O}$ mais consistente elemento da moral social é a concepção moral da profissão, e a condição primária desta é o saber, o cuidado, o apuro, a atenção e perfeição com que o trabalho profissional é feito (SÉRGIO, 1915/2008, p. $59-60)$.

Assim, o ideal anglo-saxónico do self-government, da autonomia e da iniciativa, deve ser adaptado a "uma escola do trabalho e da organização social do trabalho" (SÉRGIO, 1915/2008, p. 69, 119).

Nas Cartas sobre educação profissional (1916a), AS enuncia as actividades que constituem a base do primeiro período da instrução primária ("até cerca de 10 anos"); são elas as lições de coisas, os jogos, a história e o trabalhos manuais. Ora estes últimos são "centros de curiosidade científica e de acções em comunidade" e entre os seus objectivos contam-se: "Suscitar a estima do trabalho e do operário, aproximando as classes sociais e abalando os preconceitos de um 'grémio social cujas feições características foram por séculos o madraço e o mendigo' (Herculano)" (SÉRGIO, 1916a/2008, p. 174-177); o trabalho só tem valor educativo quando a ele vem associado o esforço e a reflexão. Discorrendo sobre o ensino da história, AS afirma:

o objectivo final do seu ensino é proporcionar ao aluno o conhecimento dos problemas da história contemporânea, os aspectos sociais e económicos da vida da actualidade. Proponho que o estudo fundamental, aqui como sempre, seja o estudo do Trabalho, a análise dos seus problemas actuais no 
pretérito condicionamento (SÉRGIO, 1916a/2008, p. $182)$.

A relação entre prática e teoria é salientada quando diz:

Cumpre que o trabalho profissional e o científico se actuem mutuamente, formando um círculo: o trabalho profissional conduz à ciência, e depois a ciência ao trabalho profissional (...) Todo o trabalho profissional quando devidamente esmiuçado, implica com o círculo inteiro dos nossos conhecimentos, e mostra a cultura transmitindo-se de geração em geração, como resultado de um trabalho persistente da humanidade (SÉRGIO, 1916a/2008, pp. 182, 184).

AS resume os princípios da sua pedagogia afirmando: "O Trabalho como alicerce, como programa e como meio: o trabalho como instrumento de todo o progresso de consciência" (SÉRGIO, 1916a/2008, p.186).

No texto de 1918, O ensino como factor do ressurgimento nacional, AS dirá que na sua doutrina da 'educação profissional' a educação geral sai "sistematicamente das actividades das profissões. Cada actividade profissional seria chamada a dar o máximo de educação geral que é possível tirar dela” (SÉRGIO, 1918a/2008, p. 236). Respondendo aos que o acusam de propor uma pedagogia utilitária, afirma que o seu ideal de trabalho é de todo diverso daquele que descreve a actividade que o operário actual realiza como escravo da máquina:

Os que me julgam 'utilitário' quando peço uma escola trabalhista mostram enterrada no seu espírito uma noção antiquadíssima do trabalho e do trabalhador; inconscientemente, vêem no trabalhador o trabalhador escravo, o trabalhador máquina, completamente 
absorvido numa faina inconsciente como operário, e joguete do político como cidadão (para estes dois papéis é que o $a b c$ é necessário e suficiente). É a velha mentalidade, incapaz de compreender a união essencialmente moderna, do 'liberal' e do útil prático, do homem humano e do produtor mecânico, da produção e da ciência (e da consciência). Não sentir a possibilidade desta união, e o seu corolário pedagógico que é a escola trabalhista, é não compreender absolutamente nada dos mais profundos problemas da pedagogia contemporânea, da educação da Democracia (SÉRGIO, 2018a/2008, p. 231).

A educação pelo trabalho convoca todas as suas interacções e implicações científicas, históricas e sócio-económicas, etc., num mundo moderno pautado pela técnica e pela indústria. Assim, o trabalho, como actividade vital, produtiva, livre e consciente, estará no centro da cultura.

\section{Proudhon: pragmatismo e pedagogia trabalhista}

Os textos de Sérgio onde se propõe a escola-município apoiada no ideal de construção da autonomia dos estudantes harmonizam-se com a ideia de Proudhon de 'self-government', que visa, como nos diz na obra de 1863 Du principe fédératif, uma "articulação entre uma sociedade económica livremente federada (...) com uma democracia política baseada no contratualismo e na capacidade de auto-admnistração por grupos naturais constituintes do organismo social" (NETO, 1988, p. 756).

Uma das importantes fontes de inspiração filosófica para o ideal de escola trabalhista é outra obra de Proudhon: De la justice dans la révolution et dans l'église (1858). Como nos recorda Kropotkin, na sua obra Origem e desenvolvimento da Ética (1922), para Proudhon, a 
sociabilidade é uma fonte primária da moralidade a qual necessita de ideais que conduzem a acção moral transformadora; a "justiça é o reconhecimento da equidade e da luta do homem pela igualdade como base de todas as nossas concepções morais", tendo como ponto de partida o sentimento da dignidade humana, (KROPOTKIN, 1922, pp. 172, 175). Nessa obra de 1858 , é tematizado o conceito de trabalho, o qual é um elemento central e estruturante do mosaico de concepções filosóficas do pensador de Besançon. Com ele se ilumina a sua filosofia da acção, valorizadora do sujeito que se quer pessoa; por isso Proudhon se interessa mais pelo trabalhador do que pelo produtor, uma vez que a inclinação para considerar sobretudo a produção favorece mais o interesse pelo objecto (recorde-se aqui o acordo com as reflexões de Marx sobre o trabalho alienado no fim do primeiro manuscrito de 1844). Proudhon valoriza o movimento, o dinamismo e o desenvolvimento, a ideia que o progresso humano é possível e depende de nós, do nosso trabalho, isto é da acção inteligente dirigida pela ideia de um objectivo, visando-se o estabelecimento de um equilíbrio social onde cada indivíduo encontra também a sua satisfação pessoal.

O trabalho é entendido como acção que é a fonte das ideias, e AS, em 1916, ao argumentar em favor duma íntima associação entre a prática e a teoria na construção da experiência humana e no ensino, invoca o De la justice, em concreto o 'Sixième étude: Le Travail'. É aqui que Proudhon melhor tematiza o conceito de trabalho e onde se encontra o fundamento original da reflexão sergiana. Aí se encontra a famosa passagem, que AS citou e que nós traduzimos: 
O problema da emancipação do trabalho está ligado ao da origem das ciências, de tal modo que a solução de um está absolutamente ligado à do outro, e que ambos se resolvem numa mesma teoria, a da supremacia da ordem industrial sobre todas as outras ordens do conhecimento e da arte.

A ideia, com as suas categorias, surge a partir da acção e deve retornar à acção sob risco do agente decair.

Quer isto dizer que todo o conhecimento, dito $a$ priori, a metafísica incluída, resultou do trabalho para servir de instrumento ao trabalho, contrariamente ao que ensina o orgulho filosófico e o espiritualismo religioso, acreditados pela política de todos os séculos (PROUDHON, 1858, tome 2, XXXI, pp. 214-215), cf. (SÉRGIO, 1916b, II, p. 10-11).

O sentido profundo da passagem "L'idée, avec ses catégories, naît de l'action et doit revenir à l'action, à peine de déchéance pour l'agent" é o de que a acção não admite nenhuma dicotomia entre matéria e inteligência, entre corpo e espírito. Isto porque a nossa acção é feita com o propósito de criação, cujo processo por excelência é o trabalho, o qual funde ideia e matéria. A ideia e a acção não são isoláveis, a sua síntese formando a nossa experiência. A ideia não só emerge da acção, ou seja se gera e se transmite por via da experiência, mas é a sua própria existência que depende da sua capacidade de voltar à acção, ou seja de re-orientar e ser útil na reconstrução da experiência. O trabalho, portanto produz, cria e educa; opor o trabalho intelectual ao trabalho manual é formular uma antinomia artificial, fundada sobre as forças engendradas pelo processo de exploração económico.

A pedagogia trabalhista que Proudhon preconiza, consiste em 
por um lado, fazer o aluno percorrer a série inteira de exercícios industriais, indo dos mais simples até aos mais difíceis (...) do outro lado, a extrair destes exercícios a ideia que neles está contida, tal como outrora os elementos das ciências foram extraídos dos primeiros engenhos industriais, e a conduzir o homem, pela cabeça e pelas mãos, à filosofia do trabalho, que é o triunfo da liberdade (PROUDHON 1858, tome 2, Sixième etude, XXXVIII, p. 232).

A ideia ao ser gerada pela acção é educativa, e ao aí voltar torna-se libertadora.

Proudhon recusa, tal como Dewey o virá a fazer, o dualismo teórico/prático e afirma o carácter unitário do trabalho humano, "uno e idêntico no seu plano, que é infinito nas suas aplicações, como a própria criação", propondo para o operário uma aprendizagem que abrace a totalidade do sistema industrial, uma vez que "todas as especialidades do trabalho humano são funções umas das outras". Ele vê nessa nova pedagogia, que propõe um ensino integral, uma significação revolucionária: "As consequências de uma semelhante pedagogia seriam incalculáveis. Feita abstracção do resultado económico, ela modificaria profundamente as almas e mudaria a face da humanidade" (PROUDHON, 1858, tome 2, Sixième étude, XL, pp. 236-237), cf. (HAMELINE, 2004, pp. 50, 83).

Se é certo que Proudhon censura aquela metafísica que está refém da distinção entre corpo e espírito, e cuja propagação associa à obra da Igreja, a verdade é que Proudhon valoriza uma metafísica da imanência; isso significa que a metafísica não pode ser obtida por pura contemplação, obra de puros espíritos, não podendo por isso subalternizar o trabalho na 
concretude da sua acção, antes dele deve partir. A recusa da influência da teologia sobre a metafísica é acompanhada por uma posição nãorelativista, que valoriza a metafísica :

Assim a Revolução tem o cuidado de marcar os limites da metafísica, da qual proclama contra o ateísmo a necessidade e o objecto. (...) Como ciência dos factos do pensamento puro, ou noologia experimental, a metafísica é a primeira e a última letra da ciência. (PROUDHON, 1858, tome 2, Septième étude XII, pp. 303-304).

Mas as ressonâncias pragmatistas avant-la-lettre do pensamento de Proudhon são mais extensas e profundas, pois Proudhon irá sublinhar o experimentalismo associado à acção dirigida, ao trabalho humano. Através do experimentalismo, que nele é político e económico, pode-se romper com o contexto fatalista daqueles que se apoiam na existência de verdades absolutas e imutáveis para justificar a dominação. (cf. MAROUPAS, 2015, p. 230). Ora o inquérito da verdade é sempre prospectivo - ele pode ser ou não bem sucedido, conduzindo sempre a modificações, perdas ou adições, do que se tinha por verdadeiro; é ele que abre a via do possível, cuja dimensão de incerteza e de inesperado é fundamental. O determinismo denunciado por Antero, como uma ameaça à afirmação da liberdade pela nossa consciência, é-o também por Proudhon, que, em clara linguagem fichteana, propugna por um equilíbrio entre o eu e o não-eu (PROUDHON, 1858, tome 1, Troisième étude, XXII, p. 267-268).

A experimentação que Proudhon preconiza nos seus escritos e na sua prática põe em relação o seu pragmatismo, a sua ultrapassagem da dicotomia idealismo/materialismo, e o reconhecimento do pluralismo 
como um facto universal. O pluralismo das práticas não significa nem solipsismo nem relativismo pois é possível e desejável a constituição de uma razão pública, plural na sua constituição mas de propósito sintético, que arbitra entre os diversos julgamentos, a qual se estabelece muitas vezes pela confrontação de experiências divergentes, num processo democrático, que se baseia na comunicação e na federação das diversas soluções que naturalmente surgem para um problema reconhecido idêntico, cujo horizonte regulador é o da constituição de uma experiência única, ideal nunca atingido. Assim esta razão pública ou colectiva, "gardienne de toute vérité et de toute Justice, centre et pivot de toute raison particulière" (PROUDHON, 1858, tome 2, Septième étude, XXXIV, p. 372) é um ser colectivo e plural, intersubjectivamente constituído, no qual se vai entretecendo a malha cada vez mais densa de relações concretas com que a realidade se identifica . Daí a necessidade de a educação ter uma dimensão social.

\section{Sociedade e trabalho: Dewey e Claparède}

Sérgio, entre 1914 e 1916, estuda no Institut Jean-Jacques Rousseau e desenvolve, então, o seu interesse por John Dewey (JD). Édouard Claparède, aí seu mestre, fez editar em 1913 o volume L'école et l'enfant, que reúne textos de JD. O prefácio é um dos primeiros estudos europeus sobre JD, e AS leu-o atentamente, bem como outros dos textos de JD. Claparède identifica aí as três características fundamentais da pedagogia de JD: $1^{\circ}$ ela é genética - a criança não deve ser educada a partir de fora mas sim do seu interior; a criança deve-se formar e não ser moldada, ou seja ela deve-se desenvolver; $2^{\circ}$ ela é funcional - os processos 
e as actividades psíquicas devem ser encarados como instrumentos destinados a prover à manutenção da vida, como funções, e não como processos que têm a sua razão de ser em si próprios; $3^{\circ}$ ela é social - a escola deve educar desenvolvendo os instintos sociais.

A psicologia de JD opõe-se à concepção de faculdades isoladas; operando juntas, a memória, a linguagem e a vontade

são instrumentos de acção, cujo próprio é de se adaptar a uma situação criada simultaneamente por uma circunstância exterior e por uma necessidade interior (...) é portanto vão querer colocá-las em acção fora de circunstâncias externas e internas que as tornam ao mesmo tempo necessárias e eficazes (CLAPARÈDE, 1913, p. XIX).

Entretanto, a pedagogia tradicional faz as crianças "falar, escrever, redigir, compor, dissertar, quando elas nada têm para dizer" (CLAPARÈDE, 1913, p. XIX). AS no seu exemplar anotou: "só quem tem experiências a comunicar tem alguma coisa que dizer". Assim, Claparède conclui que não se deve "apresentar as diversas disciplinas de modo pedante como fins em si (...) mas sim dá-las como instrumentos de vida, que é o que elas são na realidade" (CLAPARÈDE, 1913, p. XXII), tendo AS anotado: "eu direi: como instrumentos de trabalho".

Claparède afirma que o carácter social da pedagogia de JD é uma consequência da concepção funcional, pois "por um lado o indivíduo, sendo membro de uma sociedade, convém que seja preparado para ter uma função útil no grande organismo ao qual pertence" de onde a "tese fundamental de Dewey" a de que a escola deve "colocar a criança em condições ambientes que fazem apelo aos seus instintos sociais" 
(CLAPARÈDE, 1913, p. XXIII). Ora "o tipo de trabalho que melhor se presta à colaboração mútua é (...) o trabalho manual, sendo ele que Dewey queria colocar no centro da vida escolar", aproveitando Claparède por referir como, de modo independente, Kerschensteiner elaborou a sua concepção de Arbeitsschule (CLAPARÈDE, 1913, p. XXV). Para o pedagogo alemão as ocupações manuais não têm fim utilitário

o seu fim não é o da aprendizagem de um ofício, com vista a uma carreira profissional definida, mas sim a de ser 'métodos de vida, ou seja centros de curiosidade científica e de investigação activa, pontos de partida donde as crianças são levadas a realizar o desenvolvimento histórico do homem' (CLAPARÈDE, 1913, p. XXVII);

e Claparède conclui que a organização dos trabalhos manuais na Escola têm a "vantagem imensa de revelar à criança o valor do trabalho, a sua significação social e humana" (CLAPARÈDE, 1913, p. XXVIII), valor cuja dimensão utópica Claparède reconhece, apesar de salientar a sua aplicação na University Elementary School de Chicago. Vemos assim que a 'Escola trabalhista' que AS propõe está em harmonia com a leitura que Claparède faz da relevância social do 'learnig by doing' de JD e da pedagogia de Kerschensteiner.

JD, caso raro entre os filósofos académicos, interessou-se pelos problemas sociais e políticos de um modo muito prático e concreto, participando numa 'universidade popular' - a Hull House, em Chicago, fundada em 1889 como uma associação de trabalho social para imigrantes, sendo local de encontro de sindicalistas e de debate de questões sociais - , fundando uma escola experimental na Universidade de Chicago (1896), 
escrevendo sobre educação, presidindo a associações e intervindo em movimentos de opinião pública, comentando temas da actualidade política e do quotidiano. O seu interesse pela reforma social, fá-lo colocar a escola no centro do processo de reconstrução da sociedade: a escola, concebida como uma sociedade em miniatura é o lugar onde se deve desenvolver a cooperação, e não a competição. No manifesto $O$ meu credo pedagógico (1897a), destinado a todos os professores, lê-se:

Creio que a educação é o método fundamental de progresso social e de reforma (...) Creio que a educação é a regulação do processo de chegar a compartilhar a consciência social e que o ajuste da actividade individual com base nesta consciência social é o único método seguro de reconstrução social (DEWEY, 1897a, p. 16).

A sua crítica ao verbalismo ou carácter abstracto do ensino tradicional e a centralidade que concede à noção de interesse, mobilizador do esforço, aponta para uma Escola activa, na qual se estabelece a continuidade entre a aprendizagem escolar e o mundo do trabalho. Isso mesmo é explicitado no seu curso de Ética de 1897, onde ele define interesse como "a satisfação na transformação (working out) de uma ideia num feito", distinguindo-se assim do mero "sentimento"; como exemplos do interesse que visa a concretização de um feito (deed) per si, Dewey refere o de um pintor que está interessado em pintar o seu quadro, do jogador de xadrez que se interessa pelo seu jogo, do engenheiro interessado no seu projecto de drenagem. Portanto o interesse real mobiliza sempre o esforço para a realização do fim concreto desejado, contribuindo 
assim para o crescimento e reconstrução da experiência (DEWEY, 1897b, p. 80-81).

O ideal de sociedade em que JD está pensando, baseado na noção de dignidade da pessoa e de cooperação, não é muito diverso daquele que AS prefigura na sua adesão ao socialismo ético de um Proudhon e de um Antero. Tal é claro lendo, por exemplo, a conferência 'A escola e o progresso social', publicada no volume The school and the society (1899), em que a valorização do trabalho não-alienado vai de par com um ensino que se centra na aprendizagem a partir de tarefas concretas que "se abrem às possibilidades do espírito humano" (DEWEY, 1899, p. 32) aliando-se à arte, à ciência e à história que lhe dão um sentido global. JD afirma aí que a escola deve ser julgada pelas melhorias que traz à criança no seu desenvolvimento físico, nas suas capacidades para ler e escrever, no seu conhecimento de geografia e história, nas suas maneiras, hábitos de prontidão, ordem, engenho e sabedoria; a escola deve ser julgada por aquilo que contribui para a comunidade e para a democracia, para a possibilidade de vir a colocar ao dispor de todos as conquistas sociais, e conclui "aqui o individualismo e o socialismo coincidem" (p. 19). A "Nova Educação' (p. 20) é uma educação para uma nova sociedade, resultado de profundas mudanças, as quais tem por elemento nuclear o mundo técnicoindustrial que renova a condição do trabalho humano:

A primeira mudança que me vem à ideia, aquela que obscurece e até controla todas as outras, é a mudança industrial - a aplicação da ciência que resulta nas grandes invenções que têm utilizado as forças da natureza numa vasta escala e com custos diminutos: o 
crescimento de um mercado mundial como objecto da produção, de vastos centros de manufactura que fornecem esse mercado, de meios de comunicação rápidos e baratos (DEWEY, 1899, p. 21).

Tais mudanças afectam o próprio âmago da nossa natureza humana, nos seus aspectos mais profundos e conservadores que são os ligados às nossas convicções éticas e religiosas. Se a máquina moderna tem favorecido a situação em que os empregados são meros apêndices das máquinas, é fundamental que a educação forme os futuros trabalhadores de modo a lhes permitir "ver no seu dia de trabalho tudo o que existe nele com uma significação larga e humana" (DEWEY, 1899, p. 38). É fundamental que na consciência do trabalhador "o método, o propósito, o entendimento existam", que a sua actividade tenha significado por si própria, que o trabalhador não seja como o escravo de que falava Platão, isto é "daquele que nas suas acções não exprime as suas próprias ideias, mas as ideias de um outro homem" (p. 37- 38). A escola deve visar o "desenvolvimento de um espírito de cooperação social e de vida comunitária, devendo a disciplina na escola crescer e ser dependente deste objectivo" (p. 30). JD assinala criticamente que o modelo dominante no ensino tem, do ponto de vista ético, como 'fraqueza trágica' o “preparar os futuros membros da ordem social num meio no qual as condições do espírito social estão ausentes", usando "a competição como única medida para o sucesso" (p. 28 - 29). O que se necessita é de uma escola que permita "o treino da atenção e do juízo que se adquire quando se tem de fazer coisas por um motivo real e visando um objectivo concreto" (p. 25). O espírito da Educação Nova deve ser baseado na ideia do 
desenvolvimento da experiência (que é "a mãe da disciplina que é digna desse nome"), que é o único treino que se torna intuição:

$\mathrm{O}$ mais importante a ter em mente, no que toca à introdução de várias formas de ocupação activa, é que através delas se renova completamente o espírito da escola. Ganha-se a possibilidade de se o afiliar com a vida, de se tornar o habitat da criança, onde ela aprende vivendo directamente; em vez de ser apenas um local para aprender lições que têm uma abstracta e remota referência a um possível viver futuro. Ganhase a possibilidade de a escola se tornar numa comunidade em miniatura, numa sociedade em embrião (DEWEY, 1899, p. 31-32).

No seu Educação Cívica, AS refere explicitamente o opúsculo de JD intitulado Ethical Principles underlying education (1903), isto no momento em que expõe os princípios fundamentais do método educativo do self-government :

É sua razão primeira (...) a ideia de que se não pode adestrar uma criança para um dever social sem a fazer quinhoeira de uma vida em sociedade: se a escola the não fornece condições para genuínos actos sociais, semelhantes às que depois, adulto, encontrará, a doutrina moral resulta oca, verbalista cadavérica - e pelo tanto, ineficaz; é de necessidade absoluta que o aluno se habitue a cooperar pelo bem de uma comunidade, e que a escola reproduza o mais possível a estrutura da vida social adulta (SÉRGIO, 1915/2008, p. 80).

No Ethical Principles, JD aborda a questão ética segundo dois pontos de vista (o social e o psicológico), assinalando que "em assuntos intelectuais e espirituais" a "lei é a cooperação e a participação", censurando a educação que prepara para a competição (DEWEY, 1903, p. 
17). Para ele o trabalho manual é mais do que manual, sendo da ordem da actividade artística pois o carácter do trabalho artístico é a sua universalidade (como ensinou Kant) pelo que não deve ser sujeito à mera apropriação individual, o seu valor devendo ser partilhado por todos (p. 17). JD insiste em que a concepção que isola um conjunto de virtudes e de actos especiais (por exemplo, a disposição para obedecer a leis) para definir o plano ético é uma perspectiva redutora, formal e mesmo patológica - "o termo 'moral' não designa uma região especial ou uma porção da nossa vida" (p. 32); o ético relaciona-se profundamente com tudo o que tem que ver com a produção do carácter; tudo aquilo que lança luz sobre a constituição da sociedade e todo o treino que acresce os recursos sociais fazem parte da dimensão ética. Assim, na escola os recursos éticos a mobilizar são de estrutura trinitária: 1) a vida social 2) os métodos de ensinar e de trabalhar e 3) os estudos ou o currículo (p. 26).

Bem entendido, a socialização não é um fim em si pois uma sociedade humana válida e não medíocre, é aquela que, nas palavras de JD, é "constituída por indivíduos com qualidades pessoais significativas" (DEWEY, 1916/2016, p. 262), sendo o desenvolvimento da personalidade um fim maior da educação. De facto, se considerarmos as finalidades da educação, também aí encontramos consonância entre os pontos de vista de AS e de JD. Por exemplo AS, ilustrou a dialéctica entre meios e fins para sublinhar como a construção da personalidade é o fim maior da educação:

A personalidade é o nosso escopo: mas essa personalidade só na acção social se pode formar e desenvolver. A sociedade é um meio, mas um meio 
necessário; e para que esse meio realize o que a ele se deseja, cumpre que de certo modo nos dediquemos a ele como um fim, contanto que nunca lhe sacrifiquemos o verdadeiro fim que é a personalidade (SÉRGIO, 1915/2008, nota 19, p. 81).

\section{A arbeitsschule e o ensino de continuação de Kerschensteiner}

O pedagogo alemão Georg Kerschensteiner (1852-1932) teve especial atenção ao ensino das massas trabalhadoras, propondo as escolas de continuação, onde os jovens trabalhadores prosseguiriam a sua aprendizagem escolar ao mesmo tempo que exerciam o seu mister, modelo que AS difundiu entre nós. Kerschensteiner, que foi director das escolas públicas de Munique entre 1895 e 1919, defendeu a ideia de que as escolas se deviam ver a si mesmas como elementos produtivos da sociedade; essa ideia foi sendo desenvolvida numa série de ensaios, começando em 1901 com o premiado Die staatsbürgerliche Erziehung der deutschen Jugend (A educação cívica da juventude alemã), que foi traduzido nos EUA em 1911, tendo o seu conceito de 'trabalho produtivo' sido elaborado num texto de 1906 sobre o valor educativo do trabalho produtivo (produktiver Arbeit), o qual é vertido em inglês em 1914. Em 1910, deu uma série de conferências nos EUA, a convite de Charles R. Richards, presidente da Associação Internacional para o Fomento da Educação Industrial; em 29 de Novembro de 1910 encontrou-se com Dewey, que há muito desejava conhecer pessoalmente, para uma conversa no Faculty Club da Universidade de Columbia, em Nova York (RÖHRSs, 1999, p. 4). Tal como Dewey, Claparède e AS, Kerschensteiner adopta uma filosofia voluntarista, onde a 
vontade e o intelecto devem ir juntos, por isso fazendo central a noção de actividade. "As nossas instituições públicas e privadas, os nossos programas e horários, deviam ser julgados tanto pela sua influência sobre a vontade como pela sua influência sobre o intelecto" (KERSCHENSTEINER, 1911b, p. 55).

Kerschensteiner distingue dois tipos de aquisição de conhecimento e de habilidade (manual); por um lado, o conhecimento de segunda mão, que se apoia na memória para transmitir o adquirido por gerações anteriores, e a habilidade ou destreza mecânica, processos favorecidos pelo sistema de instrução que é usado como instrumento pelo Estado; por outro lado, o conhecimento adquirido pela própria experiência, associado à capacidade criativa, e o trabalho produtivo, por outro; ora um novo espírito educacional vem mostrando que enquanto o primeiro processo de aprendizagem tem efeitos insatisfatórios sobre o carácter e promove a divisão no interesse do aluno, o segundo, que exige maior lentidão, favorece a modéstia e a motivação para agir; realisticamente, atendendo às condições possíveis do sistema, o melhor fruto obtém-se conjugando os dois métodos (KERSCHENSTEINER, 1914, p. 50-56). O valor educativo do 'trabalho produtivo' é iluminado pela noção fundadora de actividade, uma vez que nele se decide incluir, para além do trabalho físico nãoalienado, a actividade de um jogador de xadrez, ou, genericamente, a produção de valores mentais (KERSCHENSTEINER, p. 57-59). O seu significado é também iluminado ao se considerar o jogo nas crianças, uma actividade produtiva, parcialmente inconsciente, que desenvolve a imaginação e o sentido da descoberta, e que progride por etapas (fases etárias) e que tem o seu fim em si; ao jogos sucede o interesse da criança 
pelo desporto, e, no processo de amadurecimento da actividade vai-se chegar ao 'trabalho mental realmente produtivo', exemplificado no trabalho intelectual de um cientista, actividade que implica o fixar de objectivos que estão além da actividade e o medir e ultrapassar dificuldades (KERSCHENSTEINER, 1914, p. 59-62); entra-se pois num percurso, num caminhar constante e vivo: “O trabalho produtivo dentro dos limites da capacidade do indivíduo é sempre a origem de um crescimento propositado do poder mental, buscando sempre o renovar da actividade"; o seu carácter auto-télico é fonte de beatitude: "A principal bênção do trabalho produtivo, é a de que nele se prescrevem propósitos e deveres que elevam a alegria criativa acima das penas e da confusão da vida quotidiana, tal como o homem religioso se eleva pela força da sua inquebrantável fé” (KERSCHENSTEINER, 1914, p. 63). A consonância com o 'growth of experience' de Dewey é clara. A dimensão cultural e moral, de apuramento do carácter no exercício da autonomia, que nele deve se conter é fundamental pois "uma actividade puramente intelectual da parte do cientista faz dele apenas meio homem" (KERSCHENSTEINER, 1914, p. 65).

Movido por este ideal, tomado por instrumento educacional, a criança caminhará da prática do jogo ao desenvolvimento de capacidades técnicas. Pensando em seguida no mundo laboral, o pedagogo alemão afirma que só o trabalho produtivo, cujo objectivo é determinado pelo trabalhador, dá significado à vida (KERSCHENSTEINER, 1914, p. 73); e a condição contemporânea do trabalhador é dramática: "este escravo da máquina é mais pobre do que o escravo de Roma ou da Grécia” (p. 73), não se resolvendo o problema pela simples socialização dos meios de 
produção - "Só um remédio pode aqui acudir - Dê-se-lhes uma vida plena” (p. 74), o que implica promover o espírito de cooperação: "o cuidar dos outros dá conteúdo à vida, gerando trabalho produtivo", fazendo "despertar um forte sentimento de responsabilidade que aí ganha forma prática" (p. 77, 79). Pensando nas soluções pela escola, Kerschensteiner refere a ideia de Fichte das pequenas escolas-comunidades de trabalho, (p. 77), as 'Mutualités scolaires' de Paris (p. 78) e a George Junior Republic do Estado de Nova York (p. 77). Ora, intencionalmente decerto, AS escreveu no início do seu Educação Cívica: "A noção de valor educativo das comunidades de trabalho está indicada em Fichte, que nos seus Discursos à Nação Alemã recomenda as comunidades de trabalho como importantes factores educativos", (SÉRGIO, 1915/2008 p. 59); e aí deu especial atenção à Junior Republic de R. W. George (SÉRGIO, 1915/2008, pp. 86-87, 105-111). O nome de Kerschensteiner não aparece mencionado em 1915, porque era um autor de uma nação inimiga.

Antes da Primeira Guerra Mundial, em Munique e, em geral, em qualquer cidade do Sul da Alemanha (a indústria pesada estando concentrada no Norte, em particular na região berlinense), a educação vocacional dos jovens trabalhadores consistia no aprendizado de um ofício, acção desenvolvida nos locais de produção e complementada pela frequência obrigatória, uma vez por semana, de uma escola de continuação (WINCH, 2006, p. 389). Os jovens aprendizes frequentam estas escolas de continuação após terem concluído o ensino primário elementar obrigatório. Kerschensteiner parte de uma realidade muito concreta - a da necessidade que a maioria tem de se dedicar a tarefas produtivas que lhe possam assegurar o sustento. Ele vai lutar pelo alargamento da frequência 
obrigatória deste tipo de escolas por todos aqueles que não se destinam ao liceu, aos estudos superiores, sendo estes, obviamente uma minoria de favorecidos (KERSCHENSTEINER, 1911a, pp. 166-167). Ao mesmo tempo tenta mobilizar capitais privados, de modo a que o patronato se veja directamente envolvido na formação dos jovens aprendizes. Nas escolas de continuação, o ensino vocacional deve desenvolver as capacidades que permitam transformar o trabalho numa via de auto-realização, de satisfação, evitando a estreiteza de vistas, que a formação profissional exclusiva pode implicar, através do desenvolvimento cultural e da educação cívica. Kerschensteiner tem ideias claras sobre qual deverá ser o desenvolvimento da sociedade:

A divisão do trabalho é um elemento vital da indústria. Mas a indústria não é o objectivo da sociedade humana. O objectivo da sociedade é o fomento da justiça e da cultura. E se a indústria continuar permanente e impiedosamente a desrespeitar este objectivo ela tornar-se-á um perigo, não apenas para o estado, mas também, no fim, para si mesma. Um estado democrático ou mesmo um estado constitucional que seja regido exclusivamente pela luxúria do lucro, pelo dinheiro e pelos escravosmáquinas que o dinheiro compra, está condenado à ruína inevitável, logo que as riquezas naturais do solo se exaurirem e a população se tornar demasiado densa. Nem um estado industrial se pode permitir dispensar as forças morais. Estas forças crescem mas não entre uma população de escravos-máquinas e príncipes do dinheiro. As forças morais tal como a habilidade no trabalho [skill in work] crescem no único solo que é o da satisfação no trabalho [joy in work] (KERSCHENSTEINER, 1911a, p. 168).

Kerschensteiner coloca o trabalho produtivo no centro do ensino nas 
escolas de continuação:

Se a escola de continuação, a qual só pode ter os alunos sob a sua disciplina durante uma pequena parte da semana, pretende exercer uma influência educativa sobre eles, ela deve tirar partido dos alunos aproveitando os seus interesses egoístas na vida, enobrecendo esses interesses durante o processo de aprendizagem. (...) O melhor que há a fazer é aumentar a capacidade de satisfação ['joy' no original em inglês] que os alunos têm no seu trabalho. (...) Isso só pode ser feito colocando o trabalho prático do aluno no centro de todo a actividade escolar e ensinando o aluno a o executar o melhor possível, reflectindo sobre os processos de execução do trabalho, dando razões para estes, de modo a o aluno ter completa mestria no trabalho. Deve ser tarefa da escola o agrupar a organização do ensino em torno do trabalho, o qual será feito em oficinas, laboratórios e outros locais similares. Todo o outro ensino, comercial, científico, artístico e moral deve ser feito em estreita ligação com o trabalho. Isto permitirá à escola, indo por degraus, o alargar o treino puramente técnico e mecânico para uma dada vocação no sentido de uma cada vez mais abrangente disciplina moral e intelectual (KERSCHENSTEINER, 1911a, pp. 171172).

As escolas de continuação são elemento central das medidas concretas da pedagogia trabalhista que AS defende e fazem explicitamente parte das propostas sergianas de reforma do ensino desde o Armistício de 1918, como se vê no ponto V (sobre Educação) do 'esboço do Programa de Fomento', na revista Pela Grei que dirige (SÉRGIO, 1918b, p. 11).

\section{Considerações finais}

A resolução da questão social implicava para AS uma reforma de 
mentalidades onde o papel da escola era central. Os seus ideais socialistas libertários, que partilhava com outros paladinos da Educação Nova, como Adolfo Lima (1874-1943), a sua análise histórico-sociológica de Portugal, e o seu pendor mais conciliador e reformista do que jacobino, favoreceram nele uma concepção da Educação regida por um ideal moral de trabalho que o concebia como auto-actividade criativa e veículo privilegiado da expressão de si e do exercício da cooperação e da solidariedade, sendo portanto elemento central e instrumento da constituição do carácter, da personalidade em constante crescimento e elevação à cultura. $\mathrm{O}$ próprio valor do trabalho manual vem dele ser acompanhado por actividade mental e do seu sentido social. Caberia à escola um papel central no estabelecimento, por meios pacíficos, de uma sociedade capaz de partilhar entre todos os seu membros as riquezas materiais e culturais de que a os tempos modernos ia mostrando a prodigalidade.

Para AS a correcta operacionalização dos novos métodos de ensino, valorizadores dos interesses imanentes das crianças, implicava uma fundamentação filosófica séria, um modelo antropológico coerente, aspecto frequentemente negligenciado (GONON, 2009, p. 134) . O pensamento de John Dewey, que na sua finura e subtileza dialécticas permitia afirmar posições radicais sem lhes dar a aparência de ruptura com o status quo, estava apoiado numa psicologia funcional que mostrava a importância da relação entre meios e fins no processo de constante interacção entre cada um e os outros e o ambiente, e fundava na concepção de crescimento da experiência, onde todas as nossas capacidades necessariamente buscam o seu desenvolvimento harmonioso, uma ajustada teoria da educação que entendia a moral de um modo holista, valorizando a 
interacção entre teoria e prática, isto é o esforço de incessante intelectualização da prática, o que dá ao trabalho humano uma dignidade maior.

AS soube encontrar um fio com que teceu um colar filosófico onde as pérolas trabalhistas maiores são Proudhon, Dewey e Kerschensteiner, estabelecendo assim uma relação fundadora que não foi explicitada por aqueles grandes pedagogos seus contemporâneos. Decerto o seu precoce interesse por Fichte e por Antero favoreceram essa sua intuição uma fez que Fichte fez da noção de Actividade um fulcro do seu ideário (PRÍNCIPE 2004, p. 245-261). AS identificou um núcleo pragmatista no pensamento de Proudhon: é através do trabalho, onde a acção e a ideia se complementam interagindo, que se constrói a experiência, experiência que é a de sujeitos-pessoas que vivem em relação que se quer de respeito e de reciprocidade, num processo onde o pluralismo, que afirma a primazia do possível sobre o determinismo fatalista, e a experimentação, que afirma o carácter aberto e em construção do conhecimento, o seu carácter dialógico, e que favorece o concreto sobre o geral-abstracto, permitem a construção da razão pública, a qual é superadora dos absolutos individuais. Proudhon e Dewey coincidem nas consequências educativas da sua filosofia, favorecendo a interacção entre teoria e prática, e o carácter social da racionalidade. Kerschensteiner crê que o 'trabalho produtivo', cujo paradigma é para ele, talvez, a actividade artesanal, é uma forma superior de expressão humana, sendo um meio privilegiado de constituição do carácter, incorporando elementos de auto-realização e de cidadania. Aspectos que fundam a pedagogia trabalhista de António Sérgio. 


\section{Referências}

PRÍNCIPE, J. (2004). Razão e ciência em António Sérgio. Lisboa: INCM.

CLAPARÈDE, E. (1913). Préface. In: DEWEY, J., L'école et l'enfant. Neuchâtel: Delachaux et Niestlé, 1913, p. I-XXXII.

DEWEY, J. (1897a). My pedagogical creed. New York: E. L. Kellog.

DEWEY, J. (1897b). The study of ethics A sylabus. Ann Arbor: Georg Wahr,.

DEWEY, J. (1899). The school and the society. Chicago: Chicago University Press.

DEWEY, J. (1903). Ethical principles underlying education. Chicago: Chicago University Press.

DEWEY, J. (1913). L'école et l'enfant, avec une préface de E. Claparède. Neuchâtel: Delachaux et Niestlé.

GONON, P. (2009). The quest for modern vocational education - Georg Kerschensteiner between Dewey, Weber and Simmel. Bern: Peter Lang.

HAMELINE, D. (2004). Éducation libérale contre éducation intégrale: comment qualifier une nouvelle éducation pour le peuple'. In: OTTAVI, D. L'éducation nouvelle, histoire, présence et devenir. Berlin: Peter Lang, 2004, p. 47-66.

KERSCHENSTEINER, G. (1911a). The fundamental principles of continuation schools. The School Review, 19 (3), 162 -177. https://doi.org/10.1086/435718

KERSCHENSTEINER, G. (1911b). Education for Citizenship. Rand, translated by J. A. Pressland, Chicago: McNally \& Co.

KERSCHENSTEINER, G. (1914). The schools and the nation (C. K. Ogden, Trad.). London: MacMillan. 
KROPOTKIN, P. (1922). Ethics: Origin and development (L. S. Friedland and R. Piroshnikoff, Trad.). New York: The anarchist library.

MAROUPAS, N. (2015). Pragmatisme: une philosophie anarchiste? Une généalogie : Proudhon, Bakounine, James, Dewey (Tese de doutoramento não publicada). Université Paris Ouest Nanterre la Défense, Paris.

NETO, V. (1988). Iberismo e municipalismo em J. F. Nogueira. Revista de História das Ideias, 10, 753-768. https://doi.org/10.14195/21838925_10_39

PINTASSILGO, J. (1998). República e formação de professores. Lisboa: Colibri.

PROUDHON, P.-J. (1858). De la justice dans la Révolution et dans l'Église. Trois tomes. Paris: Garnier frères.

OTTAVI, D. e al. (2004). L'éducation nouvelle, histoire, présence et devenir. Berlin: Peter Lang.

RÖHRS, H. (1999). Georg Kerschensteiner (1852-1932). disponível em: http://www.ibe.unesco.org/fileadmin/user_upload/archive/publications/Thi nkersPdf/kersches.pdf

SÉRGIO, A. (1914a/2008). O problema da cultura e o isolamento dos povos peninsulares. In: SÉRGIO, A. Ensaios sobre educação. Lisboa: INCM, 2008. p. 13-54.

SÉRGIO, A. (1914b). Pela Pedagogia do trabalho. A Águia, 27, 95-96.

SÉRGIO, A. (1915/2008). Educação Cívica. In: SÉRGIO, A. Ensaios sobre educação. Lisboa: ICNM, 2008, p. 55-122. https://doi.org/10.1142/9789812812025_0017

SÉRGIO, A. (1916a). Cartas sobre educação profissional. In: SÉRGIO, A. Ensaios sobre educação. Lisboa: ICNM, 2008, p. 167-169. 
SÉRGIO, A. (1916b). Educação geral e actividade particular (opúsculo). Lisboa.

SÉRGIO, A. (1918a). O ensino como factor do ressurgimento nacional. In: SÉRGIO, A. Ensaios sobre educação. Lisboa: INCM, 2008, p. 209-241.. Sérgio, A. (1918b). Esboço de um plano de Fomento, V- Educação. Pela Grei, suplemento ao $\mathrm{N}^{\circ} 1,10-11$.

SÉRGIO, A. (1971-1974). Ensaios. 8 tomos. Lisboa: Livraria Sá da Costa Editora (edição moderna).

SÉRGIO, A. (2008). Ensaios sobre educação. Prefácio de Manuel Ferreira Patrício. Lisboa: INCM.

WINCH, C. (2006). Georg Kerschensteiner: founding the dual system in Germany, Oxford Review of Education, 32 (3), 381-396. https://doi.org/10.1080/03054980600776530

Data de registro: 23/10/2019

Data de aceite: 09/12/2019 